\title{
付着生物調査の指数表示法
}

\author{
松 宮 義 晴* \\ (昭和 55 年 8 月 9 日受理)
}

\section{An Index Representation on the Ecological Research of the Marine Sessile Organisms}

\author{
Yoshiharu MatsumiYa \\ Faculty of Fisheries, Nagasaki University, \\ Nagasaki 852
}

(Received August 9, 1980)

抽象的記述にとどまることなく，事象を数量化し，数 理的解析を行らことは, 付着生物研究に打いても重要で 市ることは論義をまたない。特に，広い水域において長 期間にわたり一定の方法を用いて付着生物調査を実施す る場合, 統一した数量化とその指数表示は不可欠のもの である。付着生物研究の調査は構造物調查之試験板調査 の 2 方法に大別される（梶原，1979）。指数表示に用い られる数健は阿方法ともらつう，いわゆる quadrat method (わく法) や sweeping method (すくい取り 法）による単位区画（面樻）あたりの個体数である。 指数表示に恃次の上うな利点や特改をもつ。1）多く の本象を端的に，1 つの図表で説明できる。2) 水域間・ 季節間などの相対的比較ができる。共通の尺度となる。 3) 数量化とは何かという基本命題をいつる熟虑する必 要がある。何の目的もなく指数を計算しても意味がな い。4）指数表示そのものが終局の目的ではない。以後の 䂰究の重要事項を導き出す端緹となるものである。5) 倾用に打いては, 上り適切な指数を吟味 (考案)する必 要がある。各種の指数のもつ特徽・長短所を熟知しなけ ればならない。6) 1 つの指数を用いて, 多量の計算をす る場合はプログラミングできる小型卓上計算機の利用が 便利である。

指数は以下の上らに大別できる。

1. 種個体群における空間パターン, 2. 2 種の空間的 阙係, 3. 群集 (多種個体群) の解析。このうち試験板調 查では $1 \sim 3$ が, 䅎造物調查には主として 3 が使用で きる。付着生物はその生物的特徽により植物に基本をお いた指数を使用できる利点がある。一方, 試験板調査の 埸合, その板上の空間が連続的で自然の標本単位（例え

* 長崎大学水産学部
ば葉・枝・木のような離散的な居住可能空間)ではない。 従って単位区画（面積）あたりの個体数を数える時, 任 意の単位（試験板上の一区画）を定義せねばならなく, 当然区画の大きさや数が問題となる。ここでは各指数の 特徵や使用上の注意, 各指数間の差, 区画の問題に重点 をおき，上に述べた大別に従って一般によく使用される 指数を列挙する。

なお指数の実際の使用にあたっては原著論文のほか, 1 と 2 については数理生態学 (E. C. PIELOU 著, 南雲・ 合田・藤村訳, 産業図書), 3 については動物群集研究法 I. 多様性と種類組成（木元新作著, 共立出版）を参考に されたい。以下の記号はなるべく同一のものを用いた。

1. 種個体群に护ける空間パターン

いわゆる 集合度” の湘定で, 異なる時刻（季節）ある いは異なる場所での単一種の集合度の比較や，同一の場 所や時刻での異なった種個体群の集合度を比較すること ができる。離散的な単位空間における生物（主として屁 虫など）を基本的に対象としているが，試験板上に任意 の単位区画を設ける ‘区画抽出法’ や板上の個体相互の 空間的距離を用いる ‘プットレス抽出法りにも応用で きる。

具体的には，例えば東京湾におけるタテジマフジッボ の集合度の季節变化, サンカクフジッボ集合度の浜名湖 と的矢湾の差, 清水港におけるョーロッパフジツボとア メリカフジツボの差のような検討ができる。試験板その ものを一つの区画と考え, 試験地ごとの単位面積あたり の個体数を用いることにより，対象種ごとの集合度も観 察できる。

1) 区画抽出法

i. ポアソン散布指数 


$$
\begin{array}{lll}
V / m<1 & \text { の時 } & \text { 一様分布 } \\
V / m=1 & \text { の時 } & \text { ランダム分布 } \\
V / m>1 & \text { の時 } & \text { 集中分布 }
\end{array}
$$

$m$ : 単位区画あたりの平均個体数

$V:$ 分散 (不偏分散)

$V / m=1$ の時を除き, $m$ の異なる時刻や場所間の比 較をできない欠点をもつ。

ii. LLoyd（1967）による平均こみ合い度（index of mean crowdig)

$$
\stackrel{*}{m}=m+(V / m-1)
$$

集落指数 (index of patchness)

$$
C=\stackrel{*}{m} / m
$$

当は現存する個体数に依存し, ランダムな死亡によっ て密度に比例して減少する。個体の経験するこみ合い度 で, 密度に依存する成長や立体構造との関保をみるのに よいであろら。一方, $C$ は密度とは無関係で, 密度の異 なる $2 つ の$ 個体数でも同一の集落度を示す。時空間で個 体数に差の大きい空間パターンの尺度として有効であ る。

例 1. 試験板を 9 区画に切ったシロスジフジッボの 個体数

\begin{tabular}{|c|c|c|}
\hline 4 & 6 & 6 \\
\hline 12 & 4 & 14 \\
\hline 10 & 2 & 8 \\
\hline
\end{tabular}

$$
\begin{aligned}
& m=7.33 \quad \stackrel{*}{m}=8.51 \\
& V=16.00 \quad C=1.16 \\
& V / m=2.18
\end{aligned}
$$

例 2. 個体数は例 1 の半分

\begin{tabular}{|l|l|l|}
\hline 1 & 3 & 3 \\
\hline 7 & 2 & 7 \\
\hline 6 & 1 & 3 \\
\hline
\end{tabular}

$$
\begin{array}{rlr}
m & =3.67 & m=4.24 \\
V & =5.75 & C=1.16 \\
V / m & =1.57 &
\end{array}
$$

iii. Morisita (1959 a) による $I_{\delta}$

$$
\begin{gathered}
I_{\delta}=n \frac{\sum x_{i}\left(x_{i}-1\right)}{N(N-1)} \quad n: \\
I_{i}: \\
I_{\delta}<1 \text { の時 一様分布 } \\
I_{\delta}=1 \text { の時 ランダム分布 } \\
I_{\delta}>1 \text { の時 集中分布 }
\end{gathered}
$$$$
n \text { : 区画数 }
$$$$
x_{i} \text { : 各区画の個体数 }
$$$$
N\left(\sum x_{i}\right) \text { ：総個体数 }
$$

$I_{\delta}>1$ の時は平均値 $(m=N / n)$ に影響されない。 $I_{\dot{0}}<1$ の時は $m$ の影響を受けるが除去法があり，付着数の増 加と空間パターンの変化など多くの事象を観察すること ができ，一般によく用いられている。

例 $1 I_{\hat{o}}=1.15$ 例 $2 I_{\hat{o}}=1.14$

$C$ と $I_{\delta}$ 沬密度の異なる集落が占める相対的面積と, 異
なる密度間の比によりきまるが， $V / m$ と $m$ は以上の ほか平均密度の絶対的大きさに依存する久点がある。二 の点, $C$ と $I_{\hat{o}}$ の方が優れているとい方る。

\section{2） 区画抽出法における区画の大きさの影響}

試験板調查の区画は自然な標本単位でなく，必然的に 任意なため，対象生物ごとに十分な検討が必要である。 個体群が小さく密集し，互いに遠く離れた群れをなして おり，区画のへりが群れを切ることは注とんどない(切 る回数が無視できるほど少さい）場合は， $V / m$ または $(V / m-1)$ は区画の大きさに依存しない集合度の尺度 となる。

分布パターンが異なる密度を示す集落のモザイクから なり，その集落内部では個体がランダムに散在し，集落 は区画の大きさに比し大きい時は $C$ または $I_{\delta}$ が使用て きる。この仮定の正当性は，いくつかの大きさの区画を 使用して, くり返し個体群を抽出し， $C\left(I_{\delta}\right)$ が最も小さな 区画のいくつかについて変化しないかどらか判定する必 要がある。また集合度の尺度が区画の大きさによって， どのように変化するかをみて，分布パターンについての 情報を得る手法が考案されている。

3）プロットレス抽出法（最近接法）

個体相互の空間的距離を研究するもので，区画の大き さに影響されない利点がある。(1)領域全体にわたってラ ンダムに点をとり, 各々の点と最近接個体との距離を測 る方法 (2)個体群から個体をランダムに選びとれと最近 接個体の距離を測定する方法がある。試験板調查に有効 な 2 指数を以下に示す。

i. Hopkins and Skellam (1954) に上る分布集中度 俰数 (coefficient of aggregation)

$$
\begin{aligned}
& A=\sum P_{i}{ }^{2} / \sum I_{i}{ }^{2} \\
& A>1 \text { の時 } \text { 集中分布 } \\
& A=1 \text { の時 ランダム分布 } \\
& A<1 \text { の時 一様分布 }
\end{aligned}
$$

任意に設定した標本点とそれに最も近接する個体間の距 離，および任意の個体と至近個体間の距離を同数ずつ湘 定した時, それぞれの距離を $P, I$ とする。ランダム分 布からのずれの統計的有意性の検定方法も与兄られてい る。なおランダムな点に最も近い個体を個体群からラン ダムに選ばれた個体とみなすことは許されない。

ii. Clark and Evans (1954) による $R$

$$
\begin{aligned}
& R=2 \bar{r} \sqrt{\rho} \\
& R>1 \text { の時 } \\
& R=1 \text { の椂分布 } \\
& R<1 \text { の時 }
\end{aligned}
$$


$\rho$ ：密度 (単位面積あたり個体数)

$\bar{r}$ : ランダムな個体から最近接個体までの距離 $r$ の $n$ 個の平均（距離の単位は面積と同じ）

空間パターンにはいわゆる ‘強度” (密度が場所によっ て変化する程度）と“きめ’（集落がどの位きれぎれにな っているか) の 2 要素があり, $R$ は強度のみの尺度で, $A$ は強度ときめの尺度である。区画抽出法は強度のみ の尺度できめの尺度とはならず，きめを調査するために は区画の大きさをいくつも使用しなければならない。

\section{2 種の空間的関係}

これは 1 と同様に離散分布に基本をおくものである が，試験板上のような連続体の区画抽出法にも有効であ る。例えばタテジマフジッボとヨーロッパフジッボの空 間的関係，フサコケムシとナギサコケムシの空間的関 係, これらの季節 (経年) 変化や水域による差をみるこ とができる。また試験地を 1 つの区画と考えれば，ある 2 生物種の地理的分布の重複度も考察できる。

(1) 2 種とも存在, いずれか 1 種存在, 2 種とも不在の 各区画数を雨種が全く無関係に分布している場合の期待 值を基準として取扱い，相対的分布を示す ‘分布関数の 指数” (2)両種とも生息していない区画は除外して，2 種 の絶対的分布の重なり度を問題とする “分布の重なり度 指数’に大別できる。

1) 分布関数 (index of interspecific correlation) 次のような四分表による。存在・不在のかわりに個体 数の多・少でもよい(この場合, 境界值の問題は残る が)。

\begin{tabular}{|c|c|c|c|c|}
\hline \multirow{4}{*}{$\begin{array}{r}\text { 種 } \\
\mathrm{A} \\
\text {. }\end{array}$} & & 存 在 & 不 在 & 計 \\
\hline & 存 在 & $a$ & $b$ & $m=a+b$ \\
\hline & 不 在 & $c$ & $d$ & $n=c+d$ \\
\hline & 計 & $r=a+c$ & $s=b+d$ & $N=m+n=r+s$ \\
\hline
\end{tabular}

i. Yule (1912)

(区画数)

$$
Q=\frac{a d-b c}{a d+b c} \quad V=\frac{a d-b c}{\sqrt{m n r s}}
$$

ii. Cole (1949)

$$
\begin{array}{ll}
a d \geqq b c \text { の時 } & C=\frac{a d-b c}{m s} \\
a d<b c, a \leqq d \text { の時 } & C=\frac{a d-b c}{m r} \\
a d<b c, a>d \text { の時 } & C=\frac{a d-b c}{n s}
\end{array}
$$

分布型のいかんにかかわらず，そのまま統計的検定が可
能であるという長所がある。一方， $\boldsymbol{b}$ か $\boldsymbol{c}$ どちらかが 0 の時を完全な関連性, $b=c=0$ の時を絶対的な関連性と すると $Q$ および $C$ は両者の区別がつかない欠点がある。 分布が独立の時 0 正の相関の時 正 負の相関の時 負

(範囲は $-1 \sim 1$, 相関係数と類似)

前述の PIELOU の著書に関連性の生物的意味が詳細に述 ベられている。なお最近接法によるPIELOU (1961) の隔 離度指数も提案されている。

例 3 .

\begin{tabular}{l|r|r|r|r} 
& \multicolumn{3}{|c|}{$\exists$ ヨーロッハフジッボ } \\
\hline & & 存在 & 不在 & 計 \\
\cline { 2 - 5 } アメリカ & 存在 & 6 & 4 & 10 \\
フジッボ & 不在 & 3 & 7 & 10 \\
\cline { 2 - 5 } & 計 & 9 & 11 & 20 \\
\hline
\end{tabular} (区画数)

2) 分布の重なり度指数 (index of overlapping) $C_{\delta}$ を除き範用は 0 ～で，完全に重複すると 1 とな る。

i. Dice (1945)

$$
\begin{aligned}
& A / B=\frac{a}{a+c} \quad(B \text { に対する } A \text { の重なり度 }) \\
& B / A=\frac{a}{a+b} \quad(A \text { に対する } B \text { の重なり度 })
\end{aligned}
$$

ii. BRAY (1956) の振幅対応係数 (coefficient of amplitudinal correspondence)

$$
\frac{2 a}{2 a+b+c}
$$

上の 2 指数は四分表の両種とも生息していない区画 $(d)$ を除外して考えたものである。

例 3. $A / B=0.67 \quad B / A=0.60 \frac{2 a}{2 a+b+c}=0.63$

iii. 久野 (1968)

$$
r_{0}=\frac{\sum x_{i} y_{i}}{\sqrt{\sum x_{i}{ }^{2} \sum y_{i}{ }^{2}}}
$$

$x, y:$ 任意の単位区画に見い出される両種の個体数, 平均密度が小さい時 (一般に 10 以下), 平均值の影響を 受ける欠点をもつ。

iv. Morisita (1959 b)

$$
C_{\delta}=\frac{2 \sum n_{x i} n_{y i}}{\left(\delta_{x}+\delta_{y}\right) N_{x} N_{y}}
$$

$n_{x i}, n_{y i}$ : 種 $x, y$ の区画 $i$ における個体数

$N_{x}, N_{y}$ : 種 $x, y$ の全個体数 


$$
\begin{aligned}
& \delta_{x}=\frac{\sum n_{x i}\left(n_{x i}-1\right)}{N_{x}\left(N_{x}-1\right)} \\
& \delta_{y}=\frac{\sum n_{y i}\left(n_{y i}-1\right)}{N_{y}\left(N_{y}-1\right)}
\end{aligned}
$$

上限が正確に 1 ではなく不確定であり，特に分布集中度 が低い時には過大評価を導きやすい短所をもつ。

例 4. 個体数 $\left(1 \mathrm{~cm}^{2}\right.$ あたり)

\begin{tabular}{c|cc}
\hline 区画 No. & シロボヤ & フタスジボヤ \\
\hline 1 & 6 & 5 \\
2 & 7 & 4 \\
3 & 3 & 4 \\
4 & 1 & 2 \\
5 & 5 & 8 \\
\hline 計 & 22 & 23 \\
\hline
\end{tabular}

$$
r_{0}=0.91
$$$$
C_{\delta}=1.07
$$$$
\left(\begin{array}{l}
\delta_{x}=0.21 \\
\delta_{y}=0.20
\end{array}\right)
$$

$r_{0}$ と $C_{\delta}$ は種を季節や年などと监きかえれば，ある 1 生 物種における季節 (年, 時刻) 間の重なり度も测定でき る。

\section{3） 区画の大きさの影響}

分行関数の指数については，広い区画の間隔をおかな いとみせかけの正の関連性を得ることがある。また $Q$ ・ $V \cdot C$ のような関連性の係数は対象内の, 両種にとって 不都合な土地の広さ $(d)$ の影響を受ける。

小さな区画で只，大きな区画で正の関連性を示すこと がある。この場合，区画の大きさのほか生物的な面（環 境贸素に対する許容範囲など）も考察する必要がある。 関速性と区画の大きさの関係から, 生物学的知見を深め ることも可能である。MORISITA (1959 b) は各指数の此 較を行い,これらの区画の大きさによる変化を示してい る。

3. 群集（多種個体群）の解析

1) 多様度指数 (index of diversity)

箱造物調査を行った水域, 観测点や試験板上の群集の 多栐度を示すもので，同一場所の季節变化や，異なる場 所間の比較を行える。一般に值が大きい程, 多様度が大 きい。

多梯度を構成する要素は(1)種類に関する豊富さ (species richness) を示す ‘平均多様度 (種多様度)' (2)個体 数の相対的量についての均衡性 (equitability) や均等 性・平坦さ (evenness) を示す ‘相対多様度”がある。 一般に多栚度というと(1)を示す。(2)についての記述は省 㑼する。

平均多様度には, 構造的規則性による指数や情報量に よる指数もあるが，ここでは種数と個体数を用いる指数
を列記する。

i. SimpSON (1949) の単純度指数 (index of concentrating)

$$
\lambda=\frac{\sum_{i}^{S} n_{i}\left(n_{i}-1\right)}{N(N-1)}
$$

$N$ : 総個体数

$S:$ 総種類数

$n_{i}: i$ 番目の種に属する個体数

多様度指数としては $D=1-\lambda$ として用いる。分布型に ついて，どのような関数関係でもよいという利点があ る。

ii. 森下 (1967)

$N \beta$ を繁栄指数という。

$$
\beta=1 / \lambda=\frac{N(N-1)}{\sum_{i}^{S} n_{i}\left(n_{i}-1\right)}
$$

iii. Hurlbert (1971)

\begin{tabular}{|c|c|c|}
\hline 種 No. & 個体数 & \multirow{6}{*}{$\begin{aligned} \lambda & =0.26 \\
\beta & =3.87 \\
\Delta_{1} & =0.74 \\
M & =0.58\end{aligned}$} \\
\hline 1 & 10 & \\
\hline 2 & 8 & \\
\hline 3 & 5 & \\
\hline 4 & 2 & \\
\hline 5 & 1 & \\
\hline 計 & 26 & \\
\hline
\end{tabular}

$$
\begin{aligned}
\Delta_{1} & =\sum_{i}^{S}\left(\frac{n_{i}}{N}\right)\left(\frac{N-n_{i}}{N-1}\right) \\
& =\frac{N}{N-1}\left\{1-\sum_{i}^{S}\left(\frac{n_{i}}{N}\right)^{2}\right\}
\end{aligned}
$$

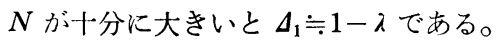

iv. McIntosh (1967)

$$
M=\frac{N-\sqrt{\sum_{i}^{S}\left(n_{i}\right)^{2}}}{N-\sqrt{N}}
$$

\section{2) 類似度指数}

構造物調査を行った $2 つ の$ 水域や試験板間の群集の類 似度を示す。1 つの調査地の季節 (㲭, 時刻) 間の類似 度も観察できる。

○共通種数による指数。一般に範囲は 0 ～1 で值の大き いほどよく類似していることを示す。

i. JACCARD (1902) による共通係数 (coefficient of community)

$$
C C=\frac{c}{a+b-c}
$$

$a, b$ : 菏水域の種類数 
$c$ ：其通に出現した種類数

ii. 野村 (1940)

$$
N S C=\frac{c}{b} \quad \text { しかし } a \geqq b
$$

比較する 2 群集の種数の洼に影響されない長所がある。 他の指数は差の増加につれ，数值が小さくなる傾向をも つ。

iii. 正宗 (1934) による相関率 (percentage of affinity)

$$
P A=\frac{1}{2}\left(\frac{c}{a}+\frac{c}{b}\right)
$$

iv. OтUKA (1936) による親和係数 (coefficient of closeness)

$$
C C^{\prime}=\frac{c}{\sqrt{a b}}
$$

v. SøRensen (1948) による類似係数 (quotinent of similarity)

$$
Q S=\frac{2 c}{a+b}
$$

vi. KULEZYŃSKI (1927)

$$
K=\frac{c}{a+b-2 c}
$$

以上の其通種数系指数は，まれに出現する種が優勢な種 に比較して過大に評価されやすいという共通の欠点があ る。

例 6. $a=18, b=15, c=10$ の時

$C C=0.43, \quad N S C=0.67, P A=0.61, \quad C C^{\prime}=0.61$

$Q S=0.61, K=0.77$

○重複度による指数

i. Morisita (1959 b)

$$
\begin{aligned}
& C_{\lambda}=\frac{2 \sum n_{1 i} n_{2 i}}{\left(\lambda_{1}+\lambda_{2}\right) N_{1} N_{2}} \quad 0 \leqq C_{2} \leqq 1 \\
& \lambda_{1}=\frac{\sum n_{1 i}\left(n_{1 i}-1\right)}{N_{1}\left(N_{1}-1\right)} \quad \lambda_{2}=\frac{\sum n_{2 i}\left(n_{2 i}-1\right)}{N_{2}\left(N_{2}-1\right)}
\end{aligned}
$$

$n_{1 i}, n_{2 i}: 1$ 組, 2 組の種 $i$ の個体数

$N_{1}, N_{2}: 1$ 組, 2 組の総㑑体数

\begin{tabular}{|c|c|c|c|c|c|c|}
\hline & $\begin{array}{l}\text { アカフ } \\
\text { ジツボ }\end{array}$ & $\begin{array}{l}\text { サンカ } \\
\text { ク }\end{array}$ & $\begin{array}{l}\text { シロス } \\
\text { ジ }\end{array}$ & $\begin{array}{l}\text { タテジ } \\
\text { マ }\end{array}$ & $\begin{array}{l}\text { アメリ } \\
\text { カ }\end{array}$ & 計 \\
\hline 油壶湾 & 6 & 7 & 3 & 2 & 0 & 18 \\
\hline 野母湾 & 4 & 7 & 0 & 3 & 2 & 16 \\
\hline
\end{tabular}

ii. Кгмото (1967)

$$
\begin{aligned}
& C_{I I}=\frac{2 \sum n_{1 i} n_{2 i}}{\left(\sum \Pi_{1}{ }^{2}+\sum \Pi_{2}^{2}\right) N_{1} N_{2}} \quad 0 \leqq C_{I I} \leqq 1 \\
& \sum \Pi_{1}^{2}=\frac{\sum n_{1 i}{ }^{2}}{N_{1}{ }^{2}} \quad \sum \Pi_{2}{ }^{2}=\frac{\sum n_{2 i}{ }^{2}}{N_{2}{ }^{2}}
\end{aligned}
$$

$C_{\lambda}$ と近似しているが， $C_{I I}$ は上限が常に 1 となる。また $C_{\lambda}$ は数值に個体数しか用いることができないが， $C_{I I}$ は パーセントなどどのような尺度でも使用可能である。

例 7. 個体数 $\left(10 \mathrm{~cm}^{2}\right.$ あたり)
フジッボ群集の類似度 $C_{\lambda}=1.05, C_{I}=0.90$ (なお測 定尺度を $1 \mathrm{~cm}^{2}$ あたりに変更すると $C_{\lambda}=-0.39, C_{I}=$ 0.90 となり, $C_{\Pi}$ は変化がない。)

百分率や情報量・構造的規則性による類似度指数もあ るが，あまり一般的でない。群集の解析の場合，全生物 種について種の同定まで可能ならば理想的である。しか し，ふつら一部については属（あるいは科・目・綱・ 門）までの分類にとどめざるを得ない。この場合，多様 度・類似度のそれぞれのもっている意味や概要の程度を 認識することが重要である。

\section{文献}

BrAY, J. R. (1956). A study of mutual occurrence of plant species. Ecol., 37, 21-28.

Clark, P.J. and F.C. Evans (1954). Distance to nearest neighbor as a measure of spatial relationships in populations. Ibid. 35, 445-453.

Cole, L.C. (1949). The measurement of interspecific association. Ibid. 30, 411-424.

Dice, L. R. (1945). Measures of the amount of ecologic association between species. Ibid. 26, 297-302.

Hopkins, B. and J.G. Skellam (1954). A new method for determining the type of distribution of plant individuals. Ann. Bot. Lond. N. S., 18, 213-227.

Hurlbert, S. H. (1971). The nonconcept of species diversity: A critique and alternative parameters. Ecol., 52, 577-586.

JACCARD, P. (1902). Gezetze der Pflanzenvertheilung in der Alpinen Region. Flora, 90, 349377.

梶原 武 (1979). 付着動物の調查法. 付着生物研究, 1 (1), 21-27.

Кгмото, S. (1967). Some quantitative analysis on the Chrysomelid fauna of the Ryukyu Archipelago. Esakia, 6, 27-54.

Kulezý́ski, S. (1927). Die Pflanzenassoziationnnen der Pieninen. Bull. int. Acad. Pol. Sci. Lett., B. Suppl. 2, 57-203.

久野英二 (1968). 水田に打ける稻ウンカ・ヨコバイ 類個体群の動態に関する研究. 九州農試菓報, 14 (2) , 131-246.

Lloyd, M. (1967). Mean crowding. J. Anim. Ecol., 36, 1-30.

正宗㦑敬 (1934)。琉球列嵦の植物地理学的研究。 日 
本生物地理学会会報, 1, 29-86.

McIntosh, R. P. (1967). An index of diversity and relation of certain concepts to diversity. Ecol., 48, 392-404.

Morisita, M. (1959a). Measuring the dispersion of individuals and analysis of the distributional patterns. Mem. Fac. Sci. Kyushu Univ. Ser. E. (Biol.), 2, 215-235.

Morisita, M. (1959b). Measuring of interspecific association and similarity between communities. Ibid., 3, 65-80.

森下正明 (1967). 京都近郊に打ける蝶の季節分布. 「自然生態学的研究，森下正明-吉良竜夫緼， 497 $+v i$. 中央公論社，東京」95-132.

野村健一 (1940). 昆虫相比較の方法特に相関法の 提唱について，九崇大農学芸雑誌，9，235-262.

Otsuka, Y. (1936). The faunal character of the
Japanese Pleistocene marine Mollusca, as evidence of climate having become colder during the Pleistocene in Japan. Biogeograph. Soc. Japan, 6, 165-170.

Pielov, E.C. (1961). Segregation and symmetry in two-species populations as studied by nearest neighbor relations. J. Ecol., 49, 255-269.

Simpson, E. H. (1949). Measurement of diversity. Nature, 163, 688.

Sørensen, T. (1948). A method of establishing groups of equal amplitude in plant sociology based on similarity of species content and its application to analyses of the vegetation on Danish commons. Biol. Skar., 5, 1-34.

Y ULE, G. U. (1912). On the methods of measuring association between two attributes. J. Roy. Statist. Soc., 75, 579-642. 